\title{
Echocardiographic assessment of subclinical left ventricular eccentric hypertrophy in adult-onset GHD patients by geometric remodeling: an observational case-control study
}

\author{
Cesare de Gregorio*1, Lorenzo Curtò ${ }^{2}$, Antonino Recupero ${ }^{1}$, \\ Patrizia Grimaldi ${ }^{1}$, Barbara Almoto², Marilena Venturino², \\ Domenico Cento ${ }^{1}$, Maria Carola Narbone ${ }^{3}$, Francesco Trimarchi ${ }^{2}$, \\ Sebastiano Coglitore ${ }^{1}$ and Salvatore Cannavò ${ }^{2}$
}

\author{
Address: ${ }^{1}$ Clinical and Experimental Department of Medicine and Pharmacology, Cardiology Unit, University Hospital of Messina, Messina, Italy, \\ ${ }^{2}$ Clinical and Experimental Department of Medicine and Pharmacology, Endocrine Unit, University Hospital of Messina, Messina, Italy and \\ ${ }^{3}$ Department of Neurosciences, University Hospital of Messina, Messina, Italy \\ Email: Cesare de Gregorio* - cesaredegregorio@alice.it; Lorenzo Curtò - lorenzocurto@hotmail.com; \\ Antonino Recupero - toninorecupero@virgilio.it; Patrizia Grimaldi - patriziagrimaldi3@virgilio.it; \\ Barbara Almoto - lorenzocurto@hotmail.com; Marilena Venturino - lorenzocurto@hotmail.com; Domenico Cento - domenico.cento@tin.it; \\ Maria Carola Narbone - MCNardone@yahoo.it; Francesco Trimarchi - trimarki@unime.it; \\ Sebastiano Coglitore - sebastiano.coglitore@unime.it; Salvatore Cannavò - scannavo@unime.it \\ * Corresponding author
}

Published: 28 February 2006

BMC Endocrine Disorders 2006, 6:1 doi:10.1186/1472-6823-6-I

This article is available from: http://www.biomedcentral.com/1472-6823/6/I

(C) 2006 de Gregorio et al; licensee BioMed Central Ltd.

This is an Open Access article distributed under the terms of the Creative Commons Attribution License (http://creativecommons.org/licenses/by/2.0), which permits unrestricted use, distribution, and reproduction in any medium, provided the original work is properly cited.
Received: 21 June 2005

Accepted: 28 February 2006

\begin{abstract}
Background: Most patients with growth hormone deficiency (GHD) show high body mass index. Overweight subjects, but GHD patients, were demonstrated to have high left ventricular mass index (LVMi) and abnormal LV geometric remodeling. We sought to study these characteristics in a group of GHD patients, in an attempt to establish the BMI-independent role of GHD.

Methods: Fifty-four patients, $28 \mathrm{~F}$ and $26 \mathrm{M}$, aged $45.9 \pm \mathrm{I}$ 3.I, with adult-onset GHD (pituitary adenomas $48.2 \%$, empty sella $27.8 \%$, pituitary inflammation $5.5 \%$, cranio-pharyngioma $3.7 \%$, not identified pathogenesis $14.8 \%$ ) were enrolled. To minimize any possible interferences of BMI on the aim of this study, the control group included 20 age- and weight-matched healthy subjects. The LV geometry was identified by the relationship between LVMi (cut-off $125 \mathrm{~g} / \mathrm{m}^{2}$ ) and relative wall thickness (cut-off 0.45 ) at echocardiography.

Results: There was no significant between-group difference in resting cardiac morphology and function, nor when considering age-related discrepancy. The majority of patients had normal-low LVM/LVMi, but about one fourth of them showed higher values. These findings correlated to relatively high circulating IGFI and systolic blood pressure at rest. The main LV geometric pattern was eccentric hypertrophy in $22 \%$ of GHD population ( $26 \%$ of with severe GHD) and in $15 \%$ of controls $(p=N S)$.

Conclusion: Though the lack of significant differences in resting LV morphology and function, about $25 \%$ of GHD patients showed high LVMi (consisting of eccentric hypertrophy), not dissimilarly to overweight controls. This finding, which prognostic role is well known in obese and hypertensive patients, is worthy to be investigated in GHD patients through wider controlled trials.
\end{abstract}




\section{Background}

Growth hormone (GH) is essential for the regulation of body composition, nutrient metabolism, extra-cellular fluid volume, lean and fat mass, maintenance of muscle mass and strength, myocardial structure and function [15].

In the majority of the patients with adult-onset and/or congenital growth hormone deficiency (GHD), previous studies showed the presence of cardiac abnormalities, mainly consistent with reduced left ventricular (LV) wall thickness, myocardial hypotrophy, impaired LV performance at rest or exertion, often associated with obesity. Some of these findings have been related to increased cardiovascular risk [6-18].

However, there is only scant information about GHD patients who have higher LV mass (LVM). Previous clinical trials clearly demonstrated that in obese and hypertensive patients with high LVM, increased relative risk for cardiovascular events is related to abnormal LV geometric remodeling [19-23].

Given that most GHD patients show high body mass index (BMI), we managed to study the echocardiographic characteristics of LVM and LV remodeling on this account. In order to establish whether there is a BMI-independent role of GHD on cardiac mass, the study group was compared to an age- and weight-matched control group.

\section{Methods}

\section{Study population}

Fifty-four consecutive Caucasian patients, 28 women and 26 men, aged $45.9 \pm 13.1$ (range 19-67), with adult-onset GHD were enrolled from January 2000 to May 2005. The main diagnosis in these patients was pituitary adenomas in $26(48.2 \%)$, empty sella in $15(27.8 \%)$, previous pituitary inflammation in $3(5.5 \%)$, cranio-pharyngioma in 2 $(3.7 \%)$. The pathogenesis was not identified in 8 patients $(14.8 \%)$.

Isolated GHD was observed in 16 patients (29.6\%). Of the 31 patients with adenomas, inflammation or craniopharyngioma, 25 had undergone surgery and 10 also received radiotherapy.

The diagnosis of GHD was based on the decreased GH responsiveness (GH-peak) to pyridostigmine + GH releasing-hormone stimulation (oral administration of pyridostigmine $120 \mathrm{mg}$, followed, after 60 minutes, by GHRH $100 \mathrm{ng} / \mathrm{mL}$ iv) and circulating IGF-I levels [24].

The GHD patients were divided into 2 groups based on the response to test : GH-peak was $<3 \mathrm{ng} / \mathrm{mL}$ in 38 patients (group A, severe GHD), and 3 to $17 \mathrm{ng} / \mathrm{mL}$ in 16 (group B, mild GHD).

Circulating IGF-1 was also tested in the GHD population. The normality range had been previously established in our Institution as follows: a) $131-384 \mathrm{ng} / \mathrm{mL}$ in patients aged 18 to 35 , b) $100-312 \mathrm{ng} / \mathrm{mL}$ in those aged 36 to 50 , and c) $106-270 \mathrm{ng} / \mathrm{mL}$ in over $50 \mathrm{~s}$.

Free triiodothyronine (FT3) and thyroxine (FT4) were measured in all the study population.

The onset of GHD (GHD length) was identified on the basis of clinical history (first diagnosis of pituitary disease, prior surgery, and, if any, previous chemical assays).

On admission, each patient underwent clinical evaluation, including measurements of weight, height, body mass index (BMI), sitting blood pressure, heart rate, standard 12-lead electrocardiography and Doppler echocardiography.

Acute coronary syndrome, previous myocardial infarction, congestive heart failure, congenital heart disease, ventricular arrhythmias, asthma, cancer, severe renal and hepatic dysfunction were all considered as exclusion criteria.

The assessment of high blood pressure was carried out in accordance with the current guidelines [25]. Patients who showed mild-to-moderate hypertension were included in the study. The final study group was compared to an ageand weight-matched control group of 20 subjects with no history of cardiac disease, from the same geographic region.

\section{Cardiac ultrasound}

Transthoracic Doppler echocardiography was performed with a commercial ultrasound unit equipped with 2.5-3.5 $\mathrm{MHz}$ transducers in harmonic imaging. Patients were examined in the left lateral supine decubitus after $15 \mathrm{~min}$ utes resting by an experienced physician, and data stored on magneto-optical disks.

Left ventricular end-diastolic/end-systolic diameters, interventricular septum (IVS) and posterior wall (PW) thickness, absolute and indexed LV mass (LVM and LVMi), relative wall thickness (RWT $=$ IVS + PW thickness/ LV end-diastolic diameter), endocardial and midwall fractional shortening (EFS and MFS) were measured according to recommendations of the American Society of Echocardiography and other studies [21,22,26,27].

Based on the relationship between LVMi and RWT, using the cut-off values of $125 \mathrm{~g} / \mathrm{m}^{2}$ for LVMi and 0.45 for RWT, 
Table I: Demographic and clinical characteristics of the study population.

\begin{tabular}{|c|c|c|c|c|}
\hline & Severe GHD $(n=38)$ & Mild GHD (n=16) & Controls $(n=20)$ & $\mathrm{p}$-value \\
\hline Age & $44.9 \pm 14.0$ & $48.2 \pm 10.6$ & $45.5 \pm 12.0$ & NS \\
\hline Gender (M/F) & $23 / 15$ & $3 / 11$ & $9 / 11$ & NS \\
\hline NYHA class & $\mathrm{I} .3 \pm 0.5$ & $\mathrm{I} . \mathrm{I} \pm 0 . \mathrm{I}$ & $1.2 \pm 0.1$ & NS \\
\hline Body mass index & $29.7 \pm 6.8$ & $31.4 \pm 4.8$ & $28.6 \pm 4.4$ & NS \\
\hline $\mathrm{SBP}^{\prime}(\mathrm{mmHg})$ & $134.1 \pm 16.1$ & $133.6 \pm 17.6$ & $128.1 \pm 10.3$ & NS \\
\hline $\mathrm{DBP}(\mathrm{mmHg})$ & $79.5 \pm 10.8$ & $81.8 \pm 9.8$ & $78.5 \pm 11.1$ & NS \\
\hline SBP $>135$ and/or DBP $>85 \mathrm{mmHg}$ & II (28.4) & $6(37.5)$ & $5(25 \%)$ & NS \\
\hline GH-peak (ng/mL) & $0.97 \pm 0.84$ & $8.31 \pm 3.31$ & NA & $<0.0001$ \\
\hline IGF-I (ng/mL) & $94.3 \pm 64.6$ & $130.5 \pm 65.8$ & NA & $<0.05$ \\
\hline FT3 (mmol/L) & $4.2 \pm 1.2$ & $4.9 \pm 1.6$ & $5.3 \pm 0.9$ & NS \\
\hline FT4 (mmol/L) & $12.9 \pm 4.0$ & $15.5 \pm 3.8$ & $14.2 \pm 2.9$ & NS \\
\hline
\end{tabular}

Values are mean \pm SD.

Legends: DBP, Diastolic Blood Pressure; GH, Growth Hormone; IGF-I, Insulin-Like Growth Factor; NA, Not Applicable; NYHA, New York Heart Association Functional Class; SBP, Systolic Blood Pressure; FT3, Free Triiodothyronine; FT4, Free Thyroxine.

both in men and women, the following geometric models were identified: normal geometry, for RWT $\leq 0.45$ and $\mathrm{LVMi} \leq 125 \mathrm{~g} / \mathrm{m}^{2} ;$ concentric remodeling, for RWT $>0.45$ and $\mathrm{LVMi} \leq 125 \mathrm{~g} / \mathrm{m}^{2}$; eccentric hypertrophy, for RWT $\leq 0.45$ and LVMi $>125 \mathrm{~g} / \mathrm{m}^{2}$; and concentric hypertrophy, for RWT $>0.45$ and $\mathrm{LVMi}>125 \mathrm{~g} / \mathrm{m}^{2}[20-23]$.

The general distribution of LVM and LVMi in the GHD population was also recognised, and 3 different categories based on 2 median values were identified.

Once no wall motion abnormalities were found, LV ejection fraction was calculated by the single-plane Simpson rule method (LV diastolic volume - LV systolic volume/LV diastolic volume) from the 4-chamber apical view.

Diastolic function was evaluated by Doppler sampling at LV inflow [trans-mitral valve blood flow sampling: early (E) and late (A) peak velocity, E/A ratio, E-wave deceleration time] and the upper right pulmonary vein outflow [systolic (S) and diastolic (D) velocity, S/D ratio, and reverse atrial velocity (Ap)], in accordance with the current European guidelines [28].

\section{Statistical analysis}

Continuous variables are expressed as mean $\pm \mathrm{SD}$, except for data expressed in percents (\%). Exact Fisher test, analysis of variance with either Scheffé, Kruskal-Wallis, or chisquared test when appropriate, were used to check the between-group differences.

Subjects' median age identified the age-related differences in LVM and LV systolic/diastolic functional parameters, and the differences were checked out by Student-T test. Linear correlation between LVMi and IGF-I and GH-peak was performed and a multivariate analysis was done in order to establish the main determinants of LVMi in the whole GHD population. The null hypothesis was rejected at 2 tails for $\mathrm{p}<0.05$ (95\% CI).

\section{Results \\ Clinical features}

Demographic and clinical characteristics of the study population are displayed in Table 1 . With the exception of GH-peak and circulating IGF-1 (both lower in group A than in $\mathrm{B}, \mathrm{p}<0.0001$ and $<0.05$, respectively), there were no significant differences in basal values.

A higher, but not significant, number of females was present in group B $(68.7 \%)$ than in A $(39.5 \%)$ and C (55\%).

Growth hormone deficiency length was established from 8 to 384 months (mean value $154 \pm 115$ months).

At entry, some patients were already treated with specific substitutive hormone for hypothyroidism ( $\mathrm{n}=29$, $53.7 \%$ ), hypogonadism ( $\mathrm{n}=26,48.1 \%)$, hyposurrenalism $(n=25,46.3 \%)$ and diabetes insipidus $(n=5,9.2 \%)$, alone or in combination. Thus, FT3 and FT4 serum levels were comparable among the 3 groups.

\section{Cardiac morphology and function}

Standard 12-lead ECG showed normal sinus rhythm in each patient, with no evidence of significant arrhythmias (atrial fibrillation, atrial flutter, premature ventricular beats $>100 / \mathrm{h}$, non-sustained tachycardia) and/or ST-T wave abnormalities suggestive of coronary artery disease.

Basal echocardiographic findings are displayed in Table 2. The main difference regarded the higher prevalence of extra-pericardial fat deposit in GHD patients than in controls $(\mathrm{p}<0.001)$. 
Table 2: Resting echocardiographic measurements

\begin{tabular}{|c|c|c|c|c|}
\hline & Severe GHD $(n=38)$ & Mild GHD $(n=16)$ & Controls $(n=20)$ & $\mathrm{p}$-value \\
\hline \multicolumn{5}{|c|}{ M-mode and two-dimensional parameters } \\
\hline LVEDD $(\mathrm{mm})$ & $49.4 \pm 5.8$ & $49.1 \pm 4.0$ & $49.3 \pm 4.0$ & NS \\
\hline LVESD (mm) & $30.7 \pm 4.5$ & $29.4 \pm 3.9$ & $30.1 \pm 3.5$ & NS \\
\hline IVS (mm) & $9.8 \pm 1.8$ & $10.6 \pm 1.4$ & $10.0 \pm 1.5$ & NS \\
\hline $\mathrm{PW}(\mathrm{mm})$ & $7.8 \pm 1.4$ & $7.8 \pm 1.3$ & $8.4 \pm 1.4$ & NS \\
\hline RWT & $0.36 \pm 0.05$ & $0.38 \pm 0.05$ & $0.38 \pm 0.06$ & NS \\
\hline $\operatorname{LVM}(\mathrm{g})$ & $194.2 \pm 62.6$ & $197.8 \pm 46.6$ & $195.3 \pm 44.5$ & NS \\
\hline LVMi $\left(\mathrm{g} / \mathrm{m}^{2}\right)$ & $104.8 \pm 27.6$ & $109.1 \pm 24.9$ & $106.1 \pm 22.7$ & NS \\
\hline LVDV (ml) & $82.3 \pm 20.7$ & $77.2 \pm 19.2$ & $80.8 \pm 15.5$ & NS \\
\hline $\operatorname{LVSV}(\mathrm{ml})$ & $30.4 \pm 9.2$ & $27.4 \pm 8.3$ & $31.7 \pm 6.6$ & NS \\
\hline LA systolic area $\left(\mathrm{cm}^{2}\right)$ & $16.8 \pm 3.8$ & $15.7 \pm 2.5$ & $16.7 \pm 1.4$ & NS \\
\hline RA systolic area $\left(\mathrm{cm}^{2}\right)$ & $14.2 \pm 2.9$ & $13.6 \pm 2.2$ & $14.1 \pm 1.3$ & NS \\
\hline Pericardial adiposity & $26(68.4 \%)^{*}$ & 10 (71.4\%)* & $4(20 \%)$ & $<0.001$ \\
\hline \multicolumn{5}{|l|}{ Left ventricular function } \\
\hline EFS (\%) & $39.0 \pm 5.1$ & $40.1 \pm 5.5$ & $38.8 \pm 4.9$ & NS \\
\hline MFS (\%) & $18.6 \pm 2.7$ & $18.8 \pm 1.8$ & $18.1 \pm 2.3$ & NS \\
\hline LVEF (\%) & $63.5 \pm 5.8$ & $63.6 \pm 9.0$ & $61.5 \pm 5.3$ & NS \\
\hline Mitral E/A velocity ratio & $1.24 \pm 0.56$ & $0.99 \pm 0.27$ & $1.18 \pm 0.48$ & NS \\
\hline E-dt & $175.5 \pm 36.8$ & $195.7 \pm 53.2$ & $173.7 \pm 39.8$ & NS \\
\hline PV S/D ratio & $\mathrm{I} . \mathrm{I} \pm 0.6$ & $1.0 \pm 0.5$ & $1.3 \pm 0.3$ & NS \\
\hline PV A velocity & $28.9 \pm 3.2$ & $29.3 \pm 5.2$ & $27.3 \pm 4.2$ & NS \\
\hline
\end{tabular}

Values are mean $\pm S D$. Scheffé test for comparison of individual groups: $*_{p}<0.01$ (groups A-B vs $C$ ).

Legends: E/A, Early/late diastolic velocity at left ventricular (LV) inflow; E-dt, E-velocity deceleration time; EFS, Endocardial fractional shortening; IVS, Interventricular septal thickness; LA, Left atrium; LVDV, LV diastolic volume; LVEDD, LV end-systolic diameter; LVEF, LV ejection fraction; $L V E S D, L V$ end-systolic diameter; LVM/LVMi, absolute/indexed LV mass; LVSV, LV systolic volume; MFS, midwall fractional shortening; PV, Right superior pulmonary vein; PW, Posterior wall thickness; RA, Right atrium; RWT, Relative wall thickness; S/D, Systolic/Diastolic velocity.

Average values of LVM/LVMi were comparable among the groups. Figure 1 also shows the median-related distribution of LVM and LVMi in 3 categories (LVM $<168 \mathrm{~g}, 168-$ $244 \mathrm{~g}$, >244 g, and LVMi <98 g/m², 98-133 g/m², >133 g/ $\mathrm{m}^{2}$ ) for each study group. More than $70 \%$ of patients with severe GHD had LVM $<244 \mathrm{~g}$ and LVMi $<133 \mathrm{~g} / \mathrm{m}^{2}$.

No significant age-related difference in LVMi, RWT, and systolic functional parameters was observed within the GHD group (Figure 2). Only a decrease in mitral E/A ratio was consistent with age, the same as reported in the general population [28].

Analysis of the LV geometric remodeling showed that the majority of GHD patients and controls had "normal geometry". Twelve GHD patients (10 with severe deficiency) showed "eccentric hypertrophy" (22.2\% vs $15.0 \%$ in controls, NS). One patient from group A had "concentric remodeling" and another from the same group had "concentric hypertrophy" (Figure 3).

Four out of the 12 GHD patients with "eccentric hypertrophy" (33.3\%), the patient with "concentric remodeling" and $1 / 3$ of controls with "eccentric hypertrophy" (33.3\%) suffered from systemic hypertension (NS).
However, in comparison with the GHD patients with lownormal LVM/LVMi $(\mathrm{n}=41)$, those with high cardiac mass $(\mathrm{n}=13)$ showed greater systolic blood pressure $(131.7 \pm$ 16.3 vs $118.2 \pm 16.9 \mathrm{mmHg}$ in the former group, respectively; $\mathrm{p}=0.02)$ and diastolic blood pressure $(81.3 \pm 7.1$ vs $74.8 \pm 11.0 \mathrm{mmHg}$, respectively; $\mathrm{p}=0.06)$, measured on admission.

Overall, there was a moderate, but significant, correlation between LVMi and circulating IGF-I in the whole GHD population ( $\mathrm{r} 0.39, \mathrm{p}<0.005)$, and particularly in group A (r 0.49, p < 0.002) (Figure 4). And IGF-1 was confirmed to be the main determinant for LVMi at multivariate analysis (Table 3).

Table 3: Main determinants of LVMi in the GHD patient group at multivariate analysis.

\begin{tabular}{lcccc}
\hline Variable & Regression (B) & SE & t-value & p-value \\
\hline Age & 0.3090 & 0.3756 & 0.8229 & 0.416 \\
GHD length & 0.0056 & 0.0377 & 0.1485 & 0.883 \\
GH-peak & -0.4494 & 0.9574 & 0.4693 & 0.642 \\
IGF-I & 0.2646 & 0.0056 & 2.7553 & $0.009 *$ \\
SBP & 0.3869 & 0.3063 & 1.2633 & 0.214 \\
\hline
\end{tabular}

Constant $(C)=29.1$ 93. Determinant coefficient $(r$ squared $)=0.27$. Legends: GH, growth hormone; IGF-I, insulin-like growth factor; $S E$, standard error; SBP, systolic blood pressure. 

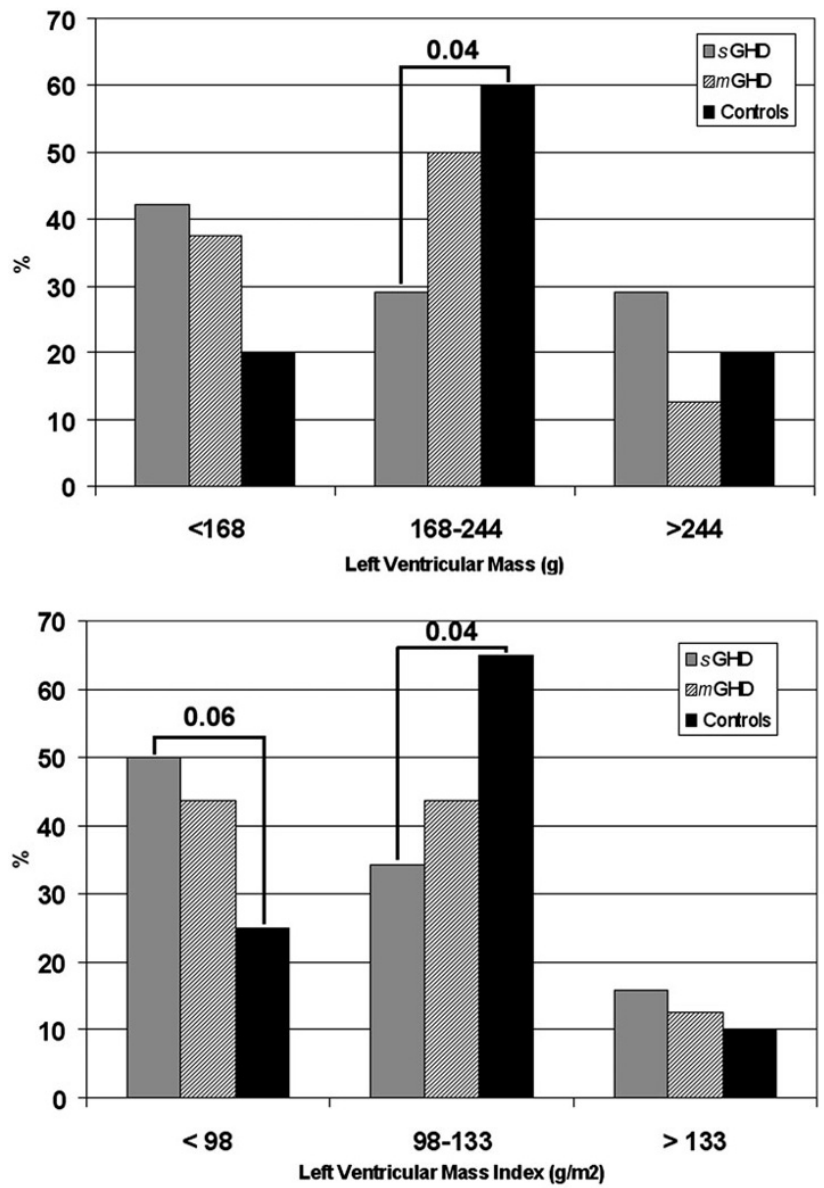

Figure I

Prevalence of left ventricular mass and left ventricular mass index in the study population. LEGEND:m-GHD, patients with mild GHD; s-GHD, patients with severe GHD.

Colour-flow mapping and Doppler sampling allowed identification of trivial mitral valve regurgitation in 31 patients from group A (81.6\%), 13 from group B (92.8\%), and 17 from group C (85\%) (NS).

\section{Discussion}

The main findings from the present study indicate that there is no significant difference in left ventricular morphology and resting function between adult-onset GHD patients and overweight healthy subjects.

As already demonstrated in other GHD populations, about $75 \%$ of our patients had low or normal LVM/LVMi [2-11]. Conversely, about a quarter of them had increased values.

We know that high LVMi emerged as the most important prognostic determinant for cardiovascular events in patients with obesity and or hypertension [19-22,27,29].
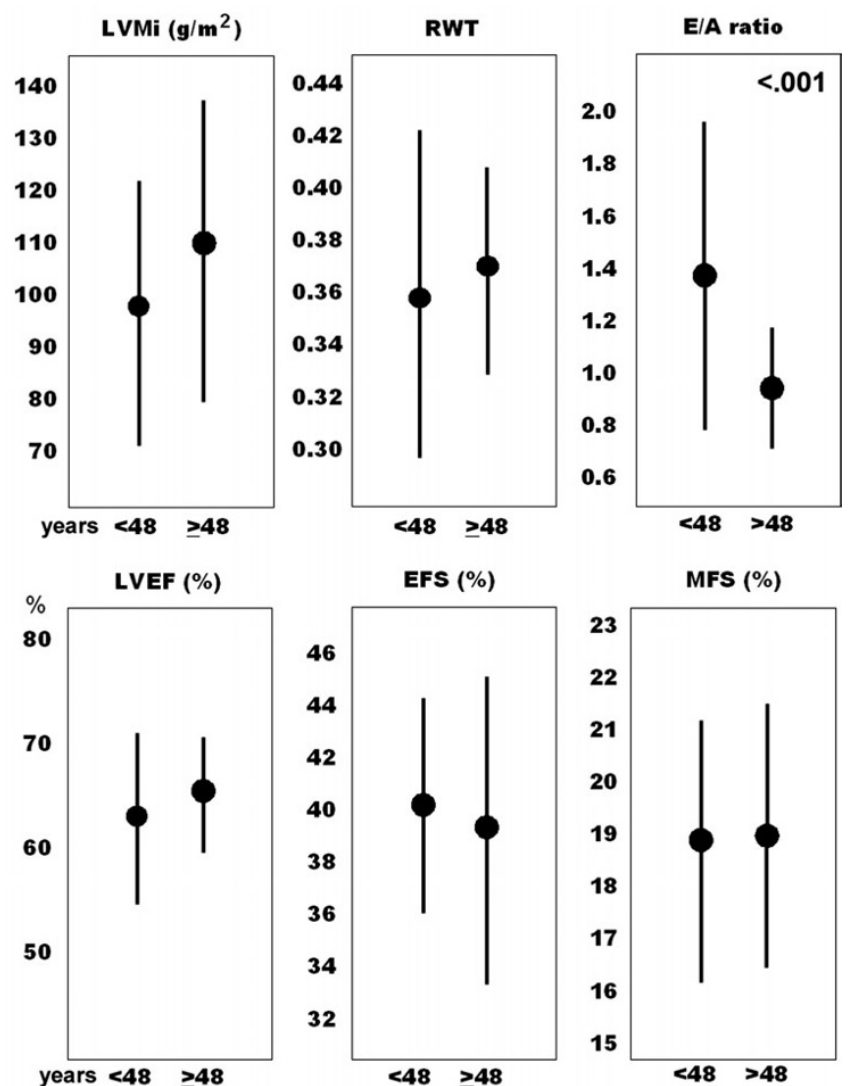

Figure 2

Age-related differences in left ventricular mass index (LVMi), relative wall thickening (RWT), mitral E/A velocity ratio (E/A ratio), left ventricular ejection fraction (LVEF), endocardial fractional shortening (EFS), and midwall fractional shortening (MFS), in the GHD population $(n=54)$.

While analysing the LV geometric remodeling, it was established that LV concentric hypertrophy has 2.1-3.6 annual odds ratio, eccentric hypertrophy 1.0-2.9, and concentric remodeling $0.3-2.4$, for negative outcomes [20-22,29].

Based on previous literature data on BMI in GHD patients, we managed to evaluate whether the analysis of LV geometric remodeling could improve the identification of those subgroups at risk for cardiovascular events, in relation with the higher LVMi. To have found LV eccentric hypertrophy in $22 \%$ of the cases ( $26 \%$ of with severe GHD) likely implies that some patients are, from this point of view, comparable to obese individuals, where this pattern usually occurs in more than $20 \%$ of cases. Given the specifc risk rate recognised in these latter category of patients, we may assume that this minority of GHD patients who show LV hypertrophy deserves further attention due to an equivalent estimated risk [19-22,29]. 


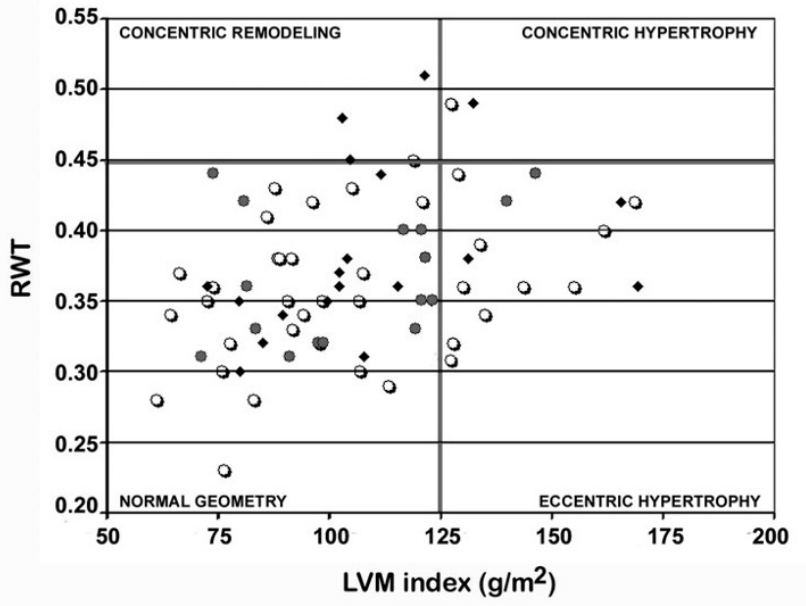

\begin{tabular}{l|cccr}
\hline Groups & Normal & CR & CH & \multicolumn{1}{c}{ EH } \\
\hline A & $26(68.4)$ & $1(2.6)$ & $1(2.6)$ & $10(26.3)$ \\
B & $14(87.5)$ & & & $2(12.5)$ \\
A+B & $40(74.0)$ & $1(1.9)$ & $1(1.9)$ & $12(22.2)$ \\
Controls & $13(65.0)$ & $3(15.0)$ & $1(5.0)$ & $3(15.0)$ \\
\hline
\end{tabular}

Figure 3

Scatter plot illustrating the left ventricular remodeling in severe (open circles), partial (full circles) GHD and controls (squares). Numbers and percents (\%) of the cases in each group are displayed in the table underneath. Legends: $C R$, concentric remodeling; $\mathrm{CH}$, concentric hypertrophy; $E H$, eccentric hypertrophy; LVMi, left ventricular mass index; $R W T$, relative wall thickness.

On the other hand, eccentric hypertrophy has been regarded as an effective way to keep systolic function into normality in obese patients, by resorting to the Starling reserve $[22,23]$. This adaptive mechanism is likely to play a role even in GHD patients, were we found no resting LV (systolic and diastolic) dysfunction in comparison to controls.

Hence, our results are in agreement with Ozbey et al, who demonstrated normal cardiac dimensions and LV systolic function at rest in the majority of their GHD patients [30].

On the contrary, depressed systolic function at rest with abnormal exertion response were recently shown by Colao et al in about $79 \%$ of patients with severe GHD, $44 \%$ with mild GHD, and $6 \%$ of controls [31].

In our opinion, such conflicting results between previous and present findings might be due to patients' age, length of GHD and extent of pituitary disease, methods to assess LV morphology and function, and local phenotypic characteristics as well [32-35].
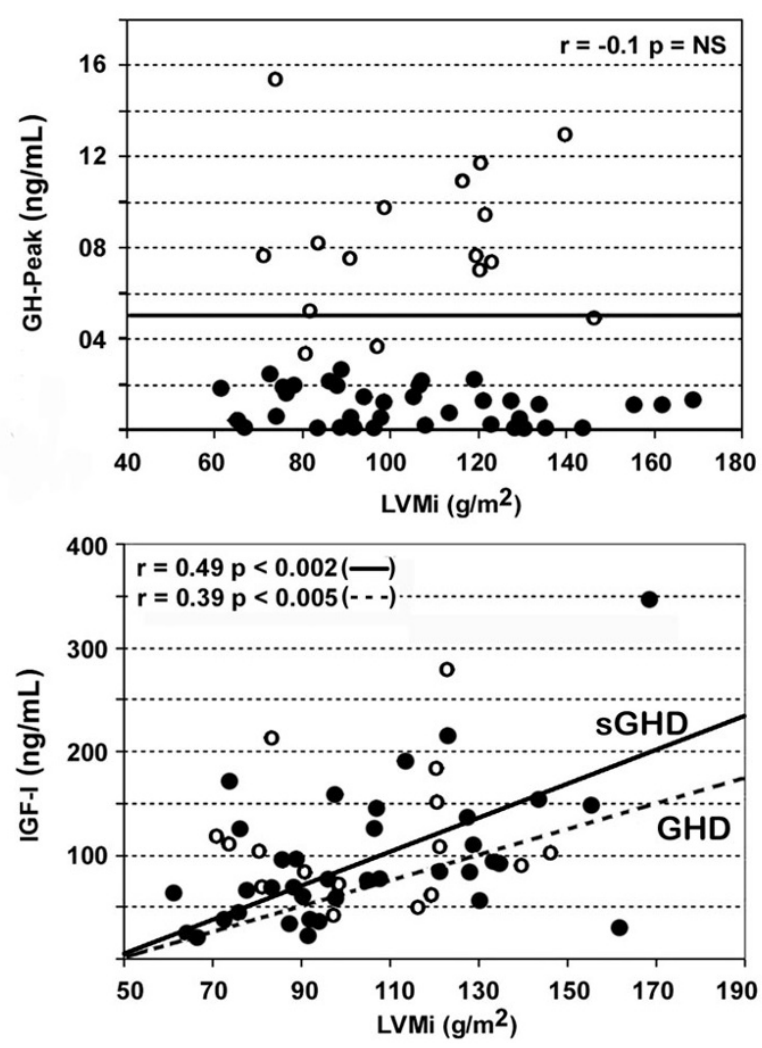

Figure 4

Linear relationship between circulating IGF-I and left ventricular mass index (LVMi) in patients with mild (open circles) and severe (full circles) GHD. Correlation r-values and $p$-values in both groups and in patients with severe GHD are reported.

The main limitations of this study is the inadequate patients' number to draw definite conclusions and the lack of information about LV performance at exercise. However, to evaluate the LV function was not a primary end-point. In fact, cardiovascular function of GHD patients, both at rest and/or exertion, can be affected by several co-morbidities, as coronary artery disease (even clinically silent), systemic hypertension, diabetes, metabolic syndrome, lung disease, multiple endocrine dysfunction, which should be all adequately screened [3136].

Beyond greater circulating IGF-1, our patients with LV hypertrophy also showed slight increase in blood pressure at baseline, which pathophysiologic role on the modulation of cardiac mass is well known [21].

The Paris prospective study, a large controlled trial where the independent prognostic role of GH was investigated in the general population, clearly demonstrated that cardiovascular disorders mainly correlate to GH increase 
rather than to deficiency [37]. Accordingly, it has been unquestionably established that acromegalic patients are at high risk for cardiovascular events, due to development of LV hypertrophy, high blood pressure, and early vascular atherosclerosis $[4,7,15,37-39]$.

\section{Conclusion}

Findings from the present study show that LV morphology and resting function are not significantly different between GHD patients and age- and weight-matched control subjects.

Overall, these patients had low-normal LVM and LVMi, and high prevalence of pericardial fat deposit. However, in about $22 \%$ of them (26\% of with severe GHD) an increase in LVMi, similar to overweight controls, can be observed. The main geometric pattern consists of LV eccentric hypertrophy.

In this series, LVMi was found to correlate with relatively high circulating IGF-1, but not to GH-peak or GHD length, and with resting systolic blood pressure.

Therefore, the analysis of the LV geometric remodeling appears to be such a simple echocardiographic method that can help physicians to better identify which category of GHD patients is likely to be at risk for cardiovascular events, strictly due to changes in cardiac mass.

Further study is needed to validate our results and establish their actual prognostic impact.

\author{
Abbreviations \\ $\mathrm{CH}$ - Concentric Hypertrophy \\ CR - Concentric Remodeling \\ DBP - Diastolic Blood Pressure \\ EFS - Endocardial Fractional Shortening \\ EH - Eccentric Hypertrophy \\ GHD - Growth Hormone Deficiency \\ IGF-1 - Insulin-like Growth Factor-1 \\ LV - Left Ventricle/Ventricular \\ LVM - Left Ventricular Mass \\ LVMi - LVM index (normalized to body surface area) \\ MFS - Midwall Fractional Shortening
}

OR - Odds Ratio

RWT - Relative Wall Thickness

SBP - Systolic Blood Pressure

\section{Competing interests}

The author(s) declare that they have no competing interests.

\section{Authors' contributions}

The project idea was conceived by Dr Cesare de Gregorio, who also collected and analysed the echocardiographic data, performed statistical analyses, drafted and revised the manuscript. All co-authors gave contribution to the manuscript and made suggestions for revisions.

Endocrine data were collected and edited by Dr Salvatore Cannavò, Dr Lorenzo Curtò, Dr Barbara Almoto, and Dr Marilena Venturino. Echocardiographic data were also collected by Dr Antonino Recupero and Dr Patrizia Grimaldi. Neurological evaluation was performed by $\mathrm{Dr}$ Maria Carola Narbone.

\section{Appendix}

Preliminary results from the study were presented as brief communications at the $5^{\text {th }}$ European Congress of Endocrinology, Turin (Italy), 2001 June 9-13.

\section{Acknowledgements}

The authors wish to thank Dr Concetta Lentini and Dr Stefano Squadrito from the Messina University Hospital for their contribution to the management of the study.

\section{References}

I. Amato G, Carella C, Fazio S, La Montagna G, Cittadini A, Sabatini D, Marciano-Mone $C$, Saccà L, Bellastella A: Body composition, bone metabolism, heart structure and function in growth hormone deficient adult before and after growth hormone replacement therapy at low doses. J Clin Endocrinol Metab 1993, 77(6): $167 \mid-1676$.

2. Carrol PV, Christ E, the members of Growth Hormone Research Society Scientific Committee, Bengtsson BA, Carlsson L, Christiansen JS, Clemmons D, Hintz R, Ho K, Laron Z, Sizonenko P, Sonksen PH, Tanaka T, Thorner M: Growth hormone deficiency in adulthood and the effects of growth hormone replacement: $A$ review. J Clin Endocrinol Metab 1998, 83(2):382-395.

3. Jorgensen JOL, Muller J, Moller J, Wolthers T, Vahl N, Juul A, Skakkerbaek NE, Christiansen JS: Adult growth hormone deficiency. Horm Res 1994, 42:235-24I.

4. Saccà L, Cittadini A, Fazio S: Growth hormone and heart. Endocr Rev 1994, I 5(5):555-573.

5. Colao A, Vitale G, Pivonello R, Ciccarelli A, Di Somma C, Lombardi G: The heart: an end-organ of $\mathbf{G H}$ action. Eur J Endocrinology 2004, I 5 I (suppI I):S93-SIOI.

6. De Boer H, Block G], Van Der Veen E: Clinical aspects of growth hormone deficiency. Endocr Rev 1995, 16:63-86.

7. Colao A, Marzullo P, Di Somma C, Lombardi G: Growth hormone and the heart. Clin Endocrinol (Oxf) 200I, 54: I37-I54.

8. Merola B, Cittadini A, Colao A, Longobardi S, Fazio S, Sabatini D, Saccà L, Lombardi G: Cardiac structural and functional abnormalities in adult patients with growth hormone deficiency. J Clin Endocrinol Metab 1993, 77(6): 1658-1661. 
9. Cittadini A, Cuocolo A, Merola B, Merla B, Fazio S, Sabatini D, Nicolai E, Colao A, Longobardi S, Lombardi G, Saccà L: Impaired cardiac performance in $\mathrm{GH}$ deficient adults and its improvement after GH replacement. Am J Physiol 1994, 267:E2 19-E225.

10. Fazio S, Cittadini A, Sabatini D, Merla B, Colao A, Biondi B, Lombardi $G$, Saccà L: Growth hormone and heart performance: a novel mechanism of cardiac wall stress regulation in humans. Eur Heart J 1997, I 8:340-347.

II. Shahi M, Beshyah SA, Hackett D, Sharp P, Jonhston DG, Foale RA: Myocardial dysfunction in treated adult hypopituitarism: a possible explanation for increased cardiovascular mortality. Br Heart J 1992, 67( I):92-96.

12. Colao A, Cuocolo A, Di Somma C, Cerbone G, Morte AM, Pivonello R, Nicolai E, Salvatore M, Lombardi G: Does the age of onset of growth hormone deficiency affect cardiac performance? A radionuclide angiography study. Clin Endocrinol (Oxf) 2000, 52(4):447-455.

13. Rosèn T, Bengtsson BA: Premature mortality due to cardiovascular diseases in hypopituitarism. A study of 333 consecutive patients. Lancet 1990, 336:285-288.

14. Bates AS, Van't Hoff W, Jones PJ, Clayton RN: The effect of hypopituitarism on life expectancy. J Clin Endocrinol Metab 1996 , 8I:II69-II72.

15. Lombardi G, Colao A, Marzullo P, Ferone D, Longobardi S, Esposito $\checkmark$, Merla B: Is growth hormone bad for your heart? Cardiovascular impact of GH deficiency and of acromegaly. J Endocrinol 1997, I 55:S33-S37.

16. Daousi C, Dunn AJ, Foy PM, MacFarlane IA, Pinkney JH: Endocrine and neuroanatomic features associated with weight gain and obesity in adult patients with hypothalamic damage. $\mathrm{Am} J$ Med 2005, I I 8(I):45-50.

17. Chanson P: Atteinte cardiovasculaire au cours du deficit en hormone de croissance (GH) chez l'adulte et effets du traitement substitutif par hormone de croissance. Sang Thromb Vaiss 1995, 7:44I-453.

18. Salerno M, Esposito V, Spinelli L, Di Somma C, Farina V, Muzzica S, de Horatio I, Lombardi G, Colao A: Left ventricular mass and function in children with $\mathbf{G H}$ deficiency before and during 12 months GH replacement therapy. Clin Endocrinol (Oxf) 2004, 60(5):630-636.

19. Levy D, Garrison RJ, Savage DD, Kannel WB, Castelli WP: Prognostic implications of echocardiographically determined left ventricular mass in the Framingham Heart Study. $N$ Engl J Med 1990, 322(22): I56|-I566.

20. Koren MJ, Devereux RB, Casale PN, Savage DD, Laragh JH: Relation of left ventricular mass and geometry to morbidity and mortality in uncomplicated essential hypertension. Ann Intern Med | 99|, I | 4(5):345-352.

21. Ganau A, Devereux RB, Roman MJ, de Simone G, Pickering TG, Saba PS, Vargiu P, Simongini I, Laragh JH: Patterns of left ventricular hypertrophy and geometric remodeling in arterial hypertension. J Am Coll Cardiol 1992, I9(7): I559-1560.

22. Devereux RB, Roman MJ: Prognostic significance of left ventricular hypertrophy and its regression [Significato prognostico dell'ipertrofia ventricolare sinistra e della sua regressione]. In Ipertrofia del cuore e dei vasi nell'ipertensione Edited by: Ganau A, Saba PS, Roman MJ, Devereux RB. Italian Society of Cardiology, Rome (Italy), Novate (Milan); 2002: I59-193.

23. de Simone G, Devereux RB, Kimball TR, Mureddu GF, Roman MJ, Contaldo F, Daniels SR: Interaction between body size and cardiac workload: influence on left ventricular mass during body growth and adulthood. Hypertension 1998, 3 I: I077- 082.

24. Ghigo E, Aimaretti G, Corneli G, Bellone J, Arvat E, Maccario M, Capanni F: Diagnosis of $\mathbf{G H}$ deficiency in adults. Growth Horm IGF Res 1998, 8(Suppl A):55-58.

25. Chobanian AV, Bakris GL, Black HR, Cushman WC, Green LA, Izzo JL Jr, Jones DW, Materson BJ, Oparil S, Wright JT Jr, Roccella EJ, Joint National Committee on Prevention Detection Evaluation, and Treatment of High Blood Pressure. National Heart, Lung, and Blood Institute, National High Blood Pressure Education Program Coordinating Committee: Seventh report of the Joint National Committee on prevention, detection, evaluation, and treatment of high blood pressure. Hypertension 2003, 42(6): I 206-I 252.

26. Schiller NB, Shah PM, Crawford M, DeMaria A, Devereux R, Feigenbaum H, Gutgesell H, Reichek N, Sahn D, Schnittger I: Recommendations for quantification of the left ventricle by two- dimensional echocardiography. American Society of Echocardiography committee on standards, subcommittee on quantitation of two-dimensional echocardiograms. J Am Soc Echocardiography 1989, 2(5):358-367.

27. de Simone G, Devereux RB, Roman MJ, Ganau A, Saba PS, Alderman $\mathrm{MH}$, Laragh JH: Assessment of left ventricular function by the midwall fractional shortening/end-systolic stress relation in human hypertension. J Am Coll Cardiol I994, 23: I444-I55I.

28. European Study Group on Diastolic Heart Failure: How to diagnose diastolic heart failure. Eur Heart J 1998, 19:990- 1003.

29. de Simone G, Verdecchia P, Pede S, Gorini M, Maggioni AP, on behalf of the MAVI Investigators: Prognosis of Inappropriate Left Ventricular Mass in Hypertension. The MAVI Study. Hypertension 2002, 40:470-476.

30. Ozbey N, Sezgil A, Oflaz H, Umman B, Orhan Y, Sencer E, Molvalilar $S$ : Left ventricular function abnormalities in hypopituitary patients with GH deficiency: Evidence for a subclinical cardiomyopathy. J Endocrinol Invest 2002, 25(7):590-597.

31. Colao A, Di Somma C, Cuocolo A, Filippella M, Rota F, Acampa W, Savastano S, Salvatore M, Lombardi G: The severity of growth hormone deficiency correlates with the severity of cardiac impairment in 100 adult patients with hypopituitarism: An observational, case-control study. J Clin Endocrinol Metab 2004, 89( I 2):5998-6004.

32. Abdu T AM, Neary R, Elhadd TA, Akber M, Clayton RN: Coronary risk in growth hormone deficient hypopituitary adults: increased predicted risk is due largely to lipid profile abnormalities. Clin Endocrinol (Oxf) 2001, 55(5):699.

33. Sassolas G, Chazot FB, Jaquet P, Bachelot I, Chanson P, Rudelli CC, Tauber JP, Allannic H, Bringer J, Roudaut N, Rohmer V, Roger P, Latapie JL, Reville P, Leutenegger M: Growth hormone deficiency in adults: an epidemiological approach. Eur J Endocrinol 1999, | 4 | (6):595-600.

34. Khan AS, Sane DC, Wannenburg T, Sonntag WE: Growth hormone, insuline-like growth factor-I and the aging cardiovascular system. Cardiovasc Res 2002, 54:25-35

35. Lissett CA, Jönssor P, Monson JP, Shalet SM, KIMS Internationa Board: Determinants of IGF-I status in a large cohort of growth hormone-deficient (GHD) subjects: the role of timing of onset of GHD. Clin Endocrinol (Oxf) 2003, 59(6):773-776.

36. McCallum RW, Petrie JR, Dominiczak AF, Connell JMC: Growth hormone deficiency and vascular risk. Clin Endocrinol 2002, 57:11-24.

37. Maison P, Balkau B, Simon D, Chanson P, Rosselin G, Eschwege E: Growth hormone as a risk for premature mortalityin heathy subjects: data from the Paris prospective study. BM] I998, 3 I6(7 I38): I |32-II33.

38. Cavalli G, de Gregorio C, Nicosia S, Cannavò S, Aragona A, Trimarchi F, Arrigo F, de Gregorio G: [Acromegalic cardiomyopathy: a morpho-functional study with color Doppler echocardiography]. Ann ltal Med Int 1992, 7(3): |4|-|47.

39. Saccà L, Napoli R, Cittadini A: Growth hormone, Acromegaly, and heart failure: an intricate triangulation. Clin Endocrinol (Oxf) 2003, 59(6):660-67I.

\section{Pre-publication history}

The pre-publication history for this paper can be accessed here:

http://www.biomedcentral.com/1472-6823/6/1/prepub 